\title{
Immunomodulatory and Anti-Diabetic Properties in Urine of Badri Cow
}

\author{
V. NAUTIYAL*AND R. C. DUBEY \\ Department of Botany and Microbiology, Gurukula Kangri Vishwavidyalaya, Haridwar-249 404 Uttarakhand, India
}

Nautiyal et al.: Immunomodulatory and Anti-diabetic properties

\begin{abstract}
The current study was aimed to investigate the immunomodulatory and anti hyperglycemic activity of cow urine using Wistar albino rats as experimental animal model. Three doses of cow urine (2, 4 and $6 \mathrm{ml} / \mathrm{kg}$ body weight) were administered to rats and selected on the basis of random sampling method. Neutrophil adhesion and delayed hypersensitivity tests were done to assess the cellular immunity, whereas humoral immunity was investigated by indirect haemagglutination titer assay. Diabetes was induced in rats by the administration of alloxan $(150 \mathrm{mg} / \mathrm{kg}$, intraperitoneal). The effect of different doses of cow urine and Glibenclamide (standard drug) was observed for consecutive $3 \mathrm{w}$. At dose 4 and $6 \mathrm{ml} / \mathrm{kg}$, a significant increase in neutrophil adhesion and delayed type hypersensitivity responses were observed. The circulating antibody titer was significantly increased in animals treated with $6 \mathrm{ml} / \mathrm{kg}$. Surprisingly, cow urine resulted in the significant decline in blood sugar level of diabetic animals as compared to diabetic control group. This shows that Badri cow urine has potential to modulate immune system via cellular and humoral immune responses. The results also indicate the dose-dependent antidiabetic activity of Badri cow urine. Hence, it may be used as alternative medicine in the treatment of diabetes and other related manifestations
\end{abstract}

Key words: Badri cow urine, Immunomodulatory activity, anti-diabetic activity

Immunomodulatory agents refer to the compounds or dietary supplements which are used to suppress or stimulate the immune system of host ${ }^{[1]}$. Immunomodulation includes induction, expression, amplification and inhibition of immune response ${ }^{[2]}$. It helps to maintain the impaired immune response caused due to immunosuppression in disease like diabetes and $\mathrm{HIV}^{[3]}$. Diabetes is a group of metabolic diseases characterized mainly by hyperglycemia with alteration in carbohydrate, protein and fat metabolism due to the inherited or acquired deficient insulin secretion or its impaired action resulting in significant morbidity and mortality ${ }^{[4]}$. The common symptoms of diabetes include excessive weight loss, polyuria, retinopathy and impaired susceptibility to infections. The available drugs for immunomodulation and diabetes are alleged 
to have serious side-effects on health. Therefore, new indigenous traditional sources need to be exploited as a substitute of chemical therapeutics.

In Ayurveda, there is a long tradition to use indigenous cow products as a remedy against various ailments. Indeed, the mixture of five cow-derived products for example urine, dung, milk, curd and ghee is called "Panchgavya". Few studies have suggested its application for health benefits ${ }^{[5,6]}$. Cow urine (CU) contains water $(95 \%)$, urea $(2.5 \%)$, and mixture of minerals, salts, hormones and enzymes $(2.5 \%)^{[7]}$. Cow derived products has been used in the treatment of many diseases such as diabetes mellitus, hypertension, obesity, ophthalmic and skin disorders ${ }^{[8,9]}$. Although, many biological properties such as antimicrobial, antioxidant and anti-inflammatory activity of cow urine have been reported ${ }^{[10-12]}$ but little is known about the immunomodulatory and antidiabetic potential of indigenous cow urine.

Badri cow is indigenous cattle breed of Uttarakhand predominantly found in hilly terrain (8500-9800 ft.) of the state. This is the first cattle breed of Uttarakhand to get certified by the National Bureau of Animal Genetic Resources (NBAGR), Karnal (India). These cows are smaller in size as compared to other indigenous cow breeds. The large population of the state depends on Badri cows for their economy and survival. Thus, Government of Uttarakhand has evinced keen interest for providing marketing facilities and commercialization of the cow products. Keeping in view the significance of cow urine in healthcare, the present study was undertaken to evaluate its immunomodulatory and antidiabetic potential using Wistar albino rats.

Badri cow urine was collected from the Cattle Breed Centre Champawat District of Uttarakhand state. Early morning mid-stream urine samples from healthy cows were collected in sterile screw capped transparent containers following aseptic precautions and brought to the laboratory. Cow urine was then filtered through Whatman No.1 filter paper to remove the debris and precipitated materials.

Laboratory breeds Wistar albino rats (150-200 g) of either sexes were procured from disease free animal house, Lala Lajpat Rai University of Veterinary and Animal sciences, Hisar, Haryana (India). All the animals were housed at $25 \pm 1^{\circ}$ in a well-ventilated Animal House under $12 \mathrm{~h}$ light/dark cycle. Paddy husk

*Address for correspondence

E-mail: nautiyalvipi1992@gmail.com was used as bedding material and replaced at regular interval to keep the animals clean. All the animals were acclimatized for $7 \mathrm{~d}$ under standard laboratory conditions prior to initiation of experiment. The animals were fed with standard pellet diet and water ad libitum in Animal House (Reg. No. 1324/GO/Re/10/CPCSEA) of the Department of Pharmaceutical sciences, Gurukula Kangri Vishwavidyalaya, Haridwar. The experimental protocol was approved by Institutional Animal Ethical Committee (Ref. No. GKV/AHF/09/2018).

Fresh sheep blood was collected from local slaughterhouse. Sheep red blood cells (SRBCs) were washed three times in large volumes of pyrogen free $0.9 \%$ normal saline and adjusted to a concentration of $0.5 \times 10^{9}$ cells $/ \mathrm{ml}$ for immunization and challenge.

The acute toxicity study was carried out following the Organization of Economic and Cooperation Development (OECD) guidelines adopting the random sampling technique. Animals of either sex were divided into four groups (six in each) and kept for overnight fasting. Group 1 was fed orally with $10 \mathrm{ml} / \mathrm{kg}$ of distilled water and served as control while Groups 2, 3 and 4 were treated with 2, 4 and $6 \mathrm{ml} / \mathrm{kg}$ of cow urine, respectively. Animals were observed for any mortality initially for first $24 \mathrm{~h}$ and then once daily to next seven days. The changes in general behaviour and toxicity symptoms of experimental animals were monitored during the study.

Group 1 rats received vehicle and served as control, whereas Groups 2, 3, and 4 were administered orally with 2,4 and $6 \mathrm{ml} / \mathrm{kg}$ body weight of cow urine, respectively for $14 \mathrm{~d}$.

Neutrophil adhesion test was performed following the method of Puri et al. ${ }^{[13]}$. The animals were pretreated with normal vehicle and different doses of cow urine for $14 \mathrm{~d}$. At the end of $14^{\text {th }} \mathrm{d}$ of treatment, blood samples were collected by retro-orbital plexus puncture into heparinized vacutainers and total leucocyte counts (TLC) and differential leucocyte counts (DLC) was done. After initial counts, blood samples were incubated with $80 \mathrm{mg} / \mathrm{ml}$ of nylon fiber for $15 \mathrm{~min}$ at $37^{\circ}$ and then blood

This is an open access article distributed under the terms of the Creative Commons Attribution-NonCommercial-ShareAlike 3.0 License, which allows others to remix, tweak, and build upon the work non-commercially, as long as the author is credited and the new creations are licensed under the identical terms

Accepted 15 October 2020

Revised 09 September 2020

Received 17 March 2020 Indian J Pharm Sci 2020;82(5):917-922 
samples were analyzed for TLC and DLC. The TLC and neutrophils (\%) gave neutrophil index (NI) of the blood sample. Neutrophil adhesion (\%) was calculated as follows:

Neutrophiladhesion $\quad(\%) \quad=\mathrm{N} \mathrm{I} \mathrm{u}-\mathrm{N} \mathrm{I} \mathrm{u} \times 100 /$ $\mathrm{NIu}$, where, $\mathrm{NIu}=$ Neutrophil index of untreated blood sample; NIt=Neutrophil index of nylon fiber treated blood sample.

Haemagglutination antibody assay was done according to the method of Fuzele et al. ${ }^{[5]}$. Rats of group 2, 3 and 4 were pre-treated with respective dose of cow urine for $14 \mathrm{~d}$. All rats were immunized with $0.5 \times 10^{9} \mathrm{SRBC} /$ rat by intraperitoneally. The day of immunization was considered as day 0 . All the animals were treated with cow urine for next $14 \mathrm{~d}$. On d 15, blood samples were collected from each rat for HA titer. The titer value was determined by titrating serum dilutions with SRBC $\left(0.025 \times 10^{9}\right.$ cells $)$ in microtiter plates. The plates were then incubated at room temperature for $2 \mathrm{~h}$ and visually examined for agglutination reaction. The maximum dilution showing visible haemagglutination reaction was assigned as HA titer.

The Delayed type hypersensitivity (DTH) response was assessed according to previously described procedure by ${ }^{[14]}$. On the day of termination of treatment with cow urine, animals were immunized subcutaneously with SRBC $\left(1 \times 10^{9}\right.$ cells $)$. On $\mathrm{d} 5$ of immunization, all the animals were again challenged with $1 \times 10^{8}$ cells in the left hind footpad, whereas right foot pad was injected with the same volume of normal saline and served as control for non-specific swelling. DTH response was examined measuring the increased foot pad thickness after $24 \mathrm{~h}$ of challenge by Vernier caliper.

Animals were kept on overnight fasting. Diabetes was induced in experimental animals by the administration of single intraperitoneal dose of freshly prepared alloxan monohydrate $(150 \mathrm{mg} / \mathrm{kg})$ in $0.9 \%$ sodium chloride ${ }^{[15]}$. Glibenclamide $(10 \mathrm{mg} / \mathrm{kg})$ was used as standard drug. On the $3^{\text {rd }} \mathrm{d}$, blood glucose level of animals was measured and the diabetic rats were divided into six groups consisting of six animals in each. The group
1, 2 and 3 was served as normal vehicle, diabetic and standard drug control, respectively. Group 4, 5 and 6 received 2, 4 and $6 \mathrm{ml} / \mathrm{kg}$ body weight of cow urine orally. Blood samples were collected from tail vein at weekly intervals till three weeks and blood sugar level of animals was analyzed by glucometer. Body weight of the animals was also recorded during this study.

The statistical significance was analyzed by using one-way Analysis of Variance (ANOVA) followed by post hoc t-test with Bonferroni's comparison. All the values were expressed as mean \pm SEM and $p<0.05$ was considered significant.

The toxicity study was designed in order to get the range of safe dose that could be used for subsequent experiments. The administration of different doses of Badri cow urine did not showed any mortality after $7 \mathrm{~d}$ even at dose $6 \mathrm{ml} / \mathrm{kg}$. The animals did not show any sign and symptoms of toxicity like diarrhea, changes in skin color, convulsion, lacrimal secretion, piloerection and changes respiratory pattern during the study.

The increased neutrophil count was observed in all treatment groups. The nylon fiber treated blood sample showed low neutrophil count due to adhesion of neutrophils to the nylon fibers. Neutrophil adhesion was found significantly $(\mathrm{p}<0.001)$ more in group 3 and 4 as compared to control (Table 1).

The hemagglutination titer was used to assess the effect of cow urine on humoral immune response. The increased titer value was observed in all treatment groups but the significant $(\mathrm{p}<0.05)$ rise was found in animals that received high dose $(6 \mathrm{ml} / \mathrm{kg})$ as compared to control group (Table 2).

DTH response was performed to determine the effect of cow urine on cell-mediated immune response. The DTH response increased significantly $(\mathrm{p}<0.05)$ at dose $2 \mathrm{ml} / \mathrm{kg}$. Although, more significant $(\mathrm{p}<0.001)$ DTH response was observed at dose 4 and $6 \mathrm{ml} / \mathrm{kg}$ (Table 2).

The administration of alloxan monohydrate $(150 \mathrm{mg} /$ $\mathrm{kg}$, intraperitoneal) showed increase fasting blood sugar level of animals on $3^{\text {rd }} \mathrm{d}$ (Fig. 1). The blood sugar

TABLE 1: NEUTROPHIL ADHESION TEST

\begin{tabular}{|c|c|c|c|c|c|c|c|}
\hline \multirow{2}{*}{ Groups } & \multicolumn{2}{|c|}{ TLC } & \multicolumn{2}{|c|}{ Neutrophil \% } & \multicolumn{2}{|c|}{ Neutrophil index (NI) } & \multirow{2}{*}{$\begin{array}{l}\text { Neutrophil } \\
\text { adhesion (\%) }\end{array}$} \\
\hline & UTB & NFTB & UTB & NFTB & UTB & NFTB & \\
\hline Group 1 (Vehicle control) & $7.4 \pm 0.13$ & $6.9 \pm 0.08$ & $25.3 \pm 0.16$ & $24.4 \pm 0.29$ & $188.4 \pm 3.46$ & $169.6 \pm 3.23$ & $9.8 \pm 2.07$ \\
\hline Group 2 (2 ml/kg) & $7.7 \pm 0.11$ & $7.1 \pm 0.08$ & $30.1 \pm 0.16$ & $27.1 \pm 0.48$ & $231.6 \pm 2.19$ & $194.8 \pm 4.16$ & $15.9 \pm 1.57$ \\
\hline Group 3 (4 ml/kg) & $7.9 \pm 0.12$ & $7.3 \pm 0.12$ & $34.5 \pm 2.4$ & $23.8 \pm 0.39$ & $272.6 \pm 3.68$ & $175.1 \pm 3.55$ & $35.7 \pm 1.53^{* * *}$ \\
\hline Group $4(6 \mathrm{ml} / \mathrm{kg})$ & $8.3 \pm 0.11$ & $7.8 \pm 0.13$ & $35.5 \pm 0.20$ & $22.0 \pm 0.56$ & $295.9 \pm 3.66$ & $172.4 \pm 6.32$ & $41.7 \pm 2.09^{* * *}$ \\
\hline
\end{tabular}

All values are expressed as mean \pm SEM of six observations. TLC-Total leucocyte count, UTB -Untreated blood, NFTB- Nylon fibre treated blood; ${ }^{* * *} \mathrm{p}<0.001$ as compared to control group. 
levels of diabetic control group remained stable, while blood sugar level decreased significantly $(p<0.01$, $\mathrm{p}<0.001)$ in all treatment groups. The treatment of cow urine once in a day up to three weeks resulted a dosedependent falls in blood sugar levels. The sugar level of animals decreased significantly $(p<0.001)$ from $7^{\text {th }} d$

TABLE 2: HAEMAGGLUTINATION (HA) TITER AND DELAYED HYPERSENSITIVITY (DTH) RESPONSE

\begin{tabular}{lccc}
\hline Group & Dose & HA Titer & $\begin{array}{c}\text { DTH response } \\
(\mathrm{mm})\end{array}$ \\
\hline Group 1 & Normal & $101.3 \pm 17.37$ & $0.26 \pm 0.31$ \\
(Control) & vehicle & & \\
Group 2 & $2 \mathrm{ml} / \mathrm{kg}$ & $149.3 \pm 21.34$ & $0.41 \pm 0.43^{*}$ \\
Group 3 & $4 \mathrm{ml} / \mathrm{kg}$ & $192.3 \pm 28.63$ & $0.56 \pm 0.31^{* * *}$ \\
Group 4 & $6 \mathrm{ml} / \mathrm{kg}$ & $362.6 \pm 69.46^{*}$ & $0.71 \pm 0.43^{* * *}$ \\
\hline
\end{tabular}

All values are expressed as mean \pm SEM of six observations. ${ }^{*} p<0.05$, ${ }^{* * *} \mathrm{p}<0.001$ as compared to control. of treatment. No significant changes were observed in blood sugar level and body weight of vehicle control animals. The reduction in body weight was found in diabetic rats which were restored by cow urine treated animals (Fig. 2). The significant weight gain was observed in animals treated with 4 and $6 \mathrm{ml} / \mathrm{kg}$ of cow urine.

In Indian traditional system of medicine 'Ayurveda', cow urine has been as used as folk medicine to get rid of several diseases. In the present study, the non-toxic effect of cow urine was established by carrying out acute toxicity studies. The different doses of cow urine $(2,4$, and $6 \mathrm{ml} / \mathrm{kg}$ ) did not showed any toxic symptoms up to the end of the study. Although, clinical trials and specific pharmacological studies need to be done prior to human consumption of cow urine and its related products. It has been reported that the pathophysiological conditions of

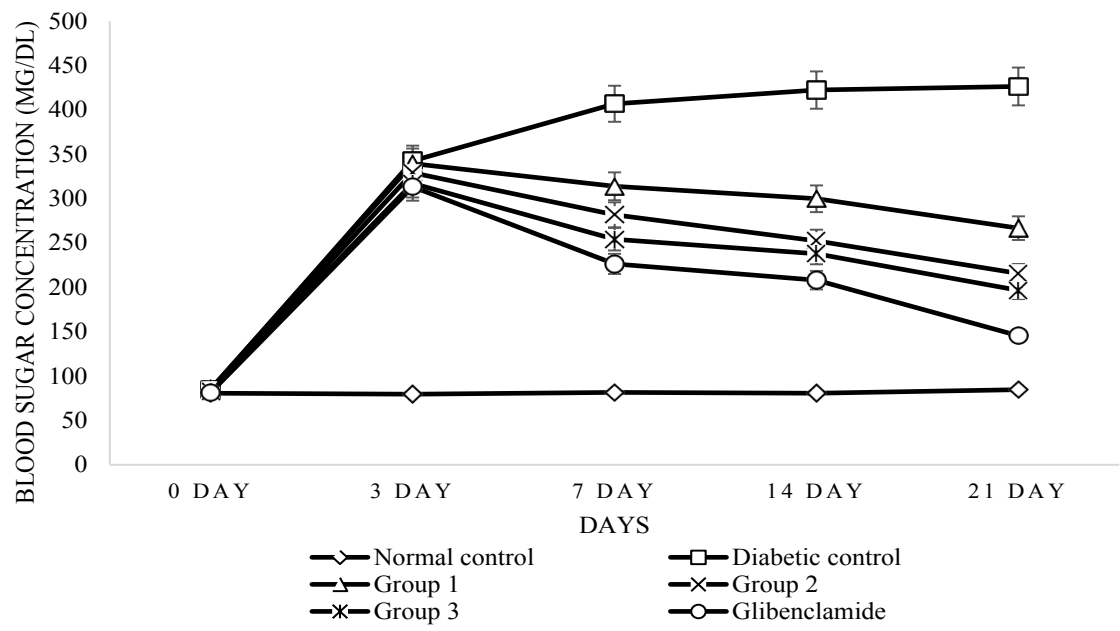

Fig. 1: The effect of cow urine on blood sugar level of diabetic rats.

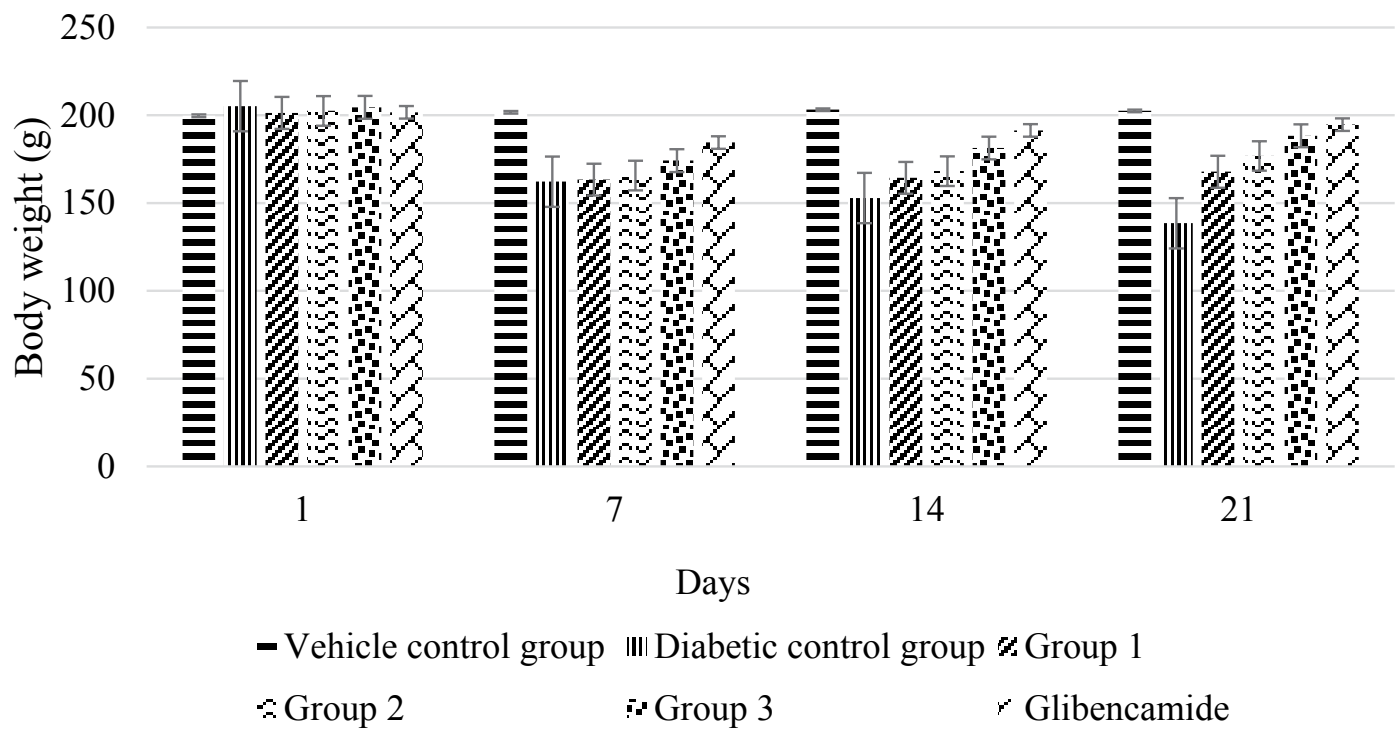

Fig. 2: The effect of different doses of cow urine on body weight $(\mathrm{g})$ of alloxan-induced diabetes in rats. 
animals in gastrointestinal and hematological disorders are closely related to humans ${ }^{[16]}$.

In this study, we found that cow urine possesses the immunostimulant and anti-diabetic activity in experimental animals. The three different methods were used to observe the cellular and humoral immune responses of experimental animals. The margination of neutrophils in blood is mediated by the interactions of $\beta 2$ integrins for firm adhesion ${ }^{[17]}$. The adherence of neutrophil to nylon fibers was found increased at dose 4 and $6 \mathrm{ml} / \mathrm{kg}$. This might be due to the upregulation of $\beta 2$ integrins. Previously, a similar study has also been done by ${ }^{[18]}$ who reported $27 \%$ neutrophil adhesion in cow urine treated animals.

The haemagglutination test was performed to confirm the effect of cow urine on humoral immune response. The increased antibody titer was found in all treatment groups but the significant increase was observed at dose $6 \mathrm{ml} / \mathrm{kg}$. This could be due to the stimulation of $\mathrm{B}$ cells that interact with antigen and proliferating and differentiating into antibody producing cell ${ }^{[19]}$. Antibodies binds to antigens specifically and neutralize as well as eliminate them by cross-linking to form latex that ingested by phagocytosis ${ }^{[20]}$. Noteworthy, the titer value was found the highest at the maximum tested dose of cow urine.

DTH response is related to the cell-mediated immune response. The response was found significantly high at both low and high doses. This indicates the ability of cow urine to enhance the cell-mediated immunity. DTH reactions are stimulated by $\mathrm{T}$ cells, macrophages and memory $\mathrm{T}$ cells ${ }^{[21]}$. Antigen-induced $\mathrm{T}$ cells are converted to lymphoblast followed by secretion of cytokines that mediate the local inflammation reactions.

The antidiabetic activity of cow urine indicates its ability to provide significant protection against diabetes in alloxan induced diabetic rats. Alloxan is an unstable organic compound which is widely used to induce diabetes in experimental animals to evaluate antidiabetic potential of any formulation or compound. The synthesis of alloxan takes place by the oxidation of uric acid ${ }^{[22]}$. It has selective toxic effect on beta cells of pancreas where it reduced to dialuric acid and then reoxidation occurs to form back alloxan that leads to generate radicals ${ }^{[23]}$. These free radicals are responsible for diabetes induction in alloxan-treated experimental animals. The excessive oxidative stress increases the free fatty acid and blood sugar level of the body. The ability of cow urine in reducing blood sugar level indicates its efficacy to neutralize the free radicals by showing antioxidant effect ${ }^{[24,25]}$. Streptozotocin-induced diabetes model used by Gururaja et al. ${ }^{[26]}$, reported significant antidiabetic effect of cow urine distillate. Alloxan-induced diabetes resulted in the characteristic weight loss of animals. Although, the significant recovery was observed in cow urine-treatment groups at the end of this study.

It may be concluded that the cellular immunity was enhanced in dose-dependent manner, while humoral immune response got increased at all doses but significant at higher dose of cow urine. The result obtained on the anti-diabetic study also revealed that cow urine has potential to maintain blood sugar level in alloxan-induced diabetic rats.

\section{Acknowledgements:}

The authors acknowledge the Head, Department of Botany and Microbiology for providing laboratory facilities, the Head, Department of Pharmaceutical Science for Animal House facility and the Project Head, Cattle Breed Centre, Champawat (Uttarakhand) for providing Badri cow urine.

\section{Conflict of Interest:}

The authors declare that they have no conflict of interest.

\section{REFERENCES}

1. Husain A, Kaushik A, Awasthi H, Singh DP, Khan R, Mani D. Immunomodulatory and antioxidant activities of fresh juice extracts of Brahmi and Guduchi. Indian J Tradit Knowl 2017;16(3):498-505.

2. Nasr-Bouzaiene N, Sassi A, Bedoui A, Krifa M, ChekirGhedira L, Ghedira K. Immunomodulatory and cellular antioxidant activities of pure compounds from Teucrium ramosissimum Desf. Tumor Biol 2016;37(6):7703-12.

3. Malagi KJ, Kamath M. Impact of herbs on immunomodulation in diabetes mellitus. J Diabetes Metab Disord Control 2018;5(2):74-6.

4. Zheng Y, Ley SH, Hu FB. Global aetiology and epidemiology of type 2 diabetes mellitus and its complications. Nat Rev Endocrinol 2018;14(2):88-98.

5. Fulzele SV, Satturwar PM, Joshi SB, Dorle AK. Study of the immunomodulatory activity of Haridradi ghrita in rats. Indian J Pharmacol 2003;35(1):51-4.

6. Raut AA, Vaidya AD. Panchgavya and cow products: A trail for the Holy Grail. J Ayurveda Integr Med 2018;9(1):64-6.

7. Khanduja S, Jain P, Sachdeva S, Phogat J. Cow urine keratopathy: A case report. J Clin Diagn Res 2017;11(4):3-4.

8. Hoh JM, Dhanashree B. Antifungal effect of cow's urine distillate on Candida species. J Ayurveda Integr Med 2017;8(4):233-7.

9. Nath R, Behera LM. Ethnomedicinal plants used against skin diseases by the tribals of Kuchinda sub-division of Sambalpur district in western Odisha. J Med Plants 2018;6(3):38-42.

10. Lavania M, Dalal J, Cheema S, Nautiyal C S, Lal B. In vitro 
study of lipid peroxidation and free radical scavenging activity of cow urine. Eur Food Res Technol 2011;232(4):703-11.

11. Ahuja A, Kumar P, Verma A, Tanwar RS. Antimicrobial activities of cow urine against various bacterial strains. Int $\mathrm{J}$ Recent Adv Pharm Res 2012;2(2):84-7.

12. Sridharamurthy NB, Manasa MN, Sowmya BA. AntiInflammatory Activity of Cow Urine Betel Vine Extract in Rats. World J Res Rev 2016;2(6):39-42.

13. Puri A, Saxena R, Saxena RP, Saxena KC, Srivastava V, Tandon JS. Immunostimulant agents from Andrographis paniculata. J Nat Prod 1993;56(7):995-9.

14. Bin-Hafeez B, Haque R, Parvez S, Pandey S, Sayeed I, Raisuddin S. Immunomodulatory effects of fenugreek (Trigonella foenum graecum L.) extract in mice. Int Immunopharmacol 2003;3(2):257-65.

15. Aruna RV, Ramesh B, Kartha VNR. Effect of beta carotene on protein glycosylation in alloxan induced diabetic rats. Indian J Exp Biol 1999;37:399-401.

16. Ogbonnia SO, Mbaka GO, Igbokwe NH, Anyika EN, Alli P, Nwakakwa N. Antimicrobial evaluation, acute and sub chronic toxicity studies of Leone Bitters, a Nigerian polyherbal formulation, in rodents. Agric Biol JN Am 2010;1(3):366-76.

17. Walzog B, Gaehtgens P. Adhesion molecules: the path to a new understanding of acute inflammation. Physiol 2000;15(3):10713.

18. Verma A, Kumar B, Manish KS, Kharya M D. Immunomodulatory potential of cow urine. Der Pharm Lettre 2011;3:507-13.
19. Sharma A, Rangari V. Immunomodulatory activity of methanol extract of Adansonia digitata L. Trop J Pharmaceut Res 2016;15(9):1923-7.

20. Shrestha P, Handral M. Evaluation of immunomodulatory activity of extract from rind of Nephelium lappaceum fruit. Int J Pharm Pharmaceut Sci 2017;9(1):38-43.

21. Afolayan FI, Erinwusi B, Oyeyemi OT. Immunomodulatory activity of curcumin-entrapped poly d, 1-lactic-co-glycolic acid nanoparticles in mice. Integr Med Res 2018;7(2):168-75.

22. Lenzen S, Panten U. Alloxan: history and mechanism of action. Diabetologia 1988;31(6):337-42.

23. Munday R. Dialuric acid autoxidation. Effects of transition metals on the reaction rate and on the generation of "active oxygen" species. Biochem Pharmacol 1988;37(3):409-13.

24. Krishnamurthi K, Dutta D, Sivanesan SD, Chakrabarti T. Protective effect of distillate and redistillate of cow's urine in human polymorphonuclear leukocytes challenged with established genotoxic chemicals. Biomed Environ Sci 2004;17(3):247-56.

25. Jarald E, Edwin S, Tiwari V, Garg R, Toppo E. Antioxidant and antimicrobial activities of cow urine. Global $\mathrm{J}$ Pharmacol 2008;2(2):20-2.

26. Gururaja MP, Joshi AB, Joshi H, Sathyanarayana D, Subrahmanyam EVS, Chandrashekhar KS. Antidiabetic potential of cow urine in streptozotocin-induced diabetic rats. Asian J Tradit Med 2010;6(1):8-13. 